\title{
Employee Resource Groups (ERGs) - An Under-Utilized and Under-Organized Way of Developing New Staff, Management and Organizational Culture
}

\author{
Alexey Kirilin ${ }^{1} \&$ Keijo Varis ${ }^{1}$ \\ ${ }^{1}$ Turku University of Applied Sciences, Master School of Engineering and Business, Finland \\ Correspondence: Keijo Varis, Turku University of Applied Sciences, Master School of Engineering and Business, \\ Finland.
}

Received: January 18, 2021

Accepted: February 2, 2021

Online Published: February 28, 2021

doi:10.5430/jms.v12n1p1

URL: https://doi.org/10.5430/jms.v12n1p1

\begin{abstract}
We evaluated impact of employees' participation in an employee resource group (ERG) on their soft skills learning and development and proposed a tool for assessing competence development that is often difficult to quantify.

ERG has a positive effect on soft skills development, however certain soft skills do not develop in the interaction between management and new employees. Some soft skills require focused and organized learning.

The role of ERG stretches beyond integration of new employees only. We propose a multidimensional paradigm where the management and organizational culture are considered as the object of development and new employees facilitate this process.
\end{abstract}

Keywords: employee resource groups, soft skills, organizational culture, development, assessment, management

\section{Introduction}

The dynamics of the modern world has increased dramatically over the past few decades, mainly due to the availability of telecommunication facilities, internet, and affordable transportation options. Digitalization and globalization processes seem to be self-accelerated and spread all over the globe, influencing almost every aspect of the way we live, work, study or make business.

Globalization has left a significant footprint on the way companies nowadays hire, develop and retain talent. Organizations are no longer bound to searching for the top hires in the local markets. On the other hand, future employees look for a good match for their skills and opportunities globally, making the entire job market a vivid and dynamic entity. Due to rapid changes in the labor market and technical progress, the employers begin to look for a skillset matching contemporary requirements and the business reality.

McKinsey\&Company reports that the skillset required in the workplace has fundamentally changed due to technical progress and innovation (Bughin et al. 2018). They point out to a mismatch between the skills the workforce offers, and the ones companies are looking for. Technical skills and basic digital skills are one specific area of mismatch.

Despite continuous demand of organizations for high-quality technical skills among the personnel, there is a growing interest in soft skills, which are vital for employees to be able to work in a team, communicate and develop. To retain the talent and foster employee development, large organizations establish internal networks. Their mission is to help employees identify opportunities and provide means for developing soft skills required for professional and personal growth as well as for enhancing performance and efficiency.

According to the forecast by Deloitte (Deloitte 2017), soft-skill intensive jobs will account for two-thirds of all jobs by 2030 , compared to half of all jobs in the year 2000 .

Despite a wide spread of virtual trainings and educational videos available on different internet platforms, educational systems lack proper programs teaching soft skills and competencies (Bennett, Dunne and Carré 1999). On the other hand, while there is a number of research studies showing a strong role and valuable contribution of the employee resource groups (ERG) in learning and development of employees, the influence of ERGs and their activity on the development and fostering of soft skills relevant to the organization appears to be underinvestigated, 
hence featuring a very interesting and useful field of research.

This study is dedicated to exploring and evaluating the role of an ERG in a global organization on the soft skills learning and development of new employees. The research findings may be useful to understand the impact of ERGs on employee development, organizational culture and interactions with management. Our research also provides an empirical tool for assessment of competences that can be applied in a broad range of organizations. The research represents a case study using both a quantitative and a qualitative research approach, i.e. a mixed-method approach.

\section{The Case Organization and Competency Areas of Soft Skills Relevant for It}

The case study was performed on the employee resource group (ERG) "Young Professionals" representing one ERGs in the global organization (> 10000 employees worldwide). The mission of the ERG is to help new employees become aware of the company's culture, support and facilitate the knowledge transfer and widen the network for new employees to enable delivering results.

There are several areas of focus for the ERG that form its strategic objective. Soft skills development per se is not directly mentioned in the ERG's mission and its strategic objectives.

Broadly, there are four competency areas of soft skills, which are relevant to the case organization:
1) Teamwork
2) Leadership and/or Proactiveness
3) Innovation
4) Customer Orientation and Focus

\section{Literature Review}

\subsection{Soft Skills - Definition and Rationale Behind Continuous Demand}

While the meaning of "technical skills" or "hard skills" appears to be intuitively clear and refer to the ability of an individual to perform certain well-defined tasks or solve problems, the situation with soft skills is more complex and requires additional input and clarification of the context.

According to a recent Deloitte report (Deloitte 2017), even though non-technical skills have become widely acknowledged as important for deliverables in addition to traditional technical (hard) skills, there is no universal definition of what soft skills mean. The European project on skills, competencies, qualifications and occupations (ESCO) sub-categorizes skills in two groups: skills specific for the job (hard skills) and transversal i.e. soft skills (ESCO 2020).

Soft skills allow people and organizations to progress and to achieve better results through the diverse ways of thinking and acting. They are often viewed as a combination of social (people) skills, communication skills, the ability to integrate and network, social and emotional intelligence (EQ) among others. Soft skills are considered personal attributes and abilities, which an individual has from the moment of birth, and scholars agree that soft skills are not easy to define (Bastos, Schleutker and Azevedo 2018; Gilbert et al. 2004; Grugulis and Vincent 2009). Often soft skills are viewed as complimentary to hard skills helping people to achieve higher performance and professionality (Rukshar and Smrutihara 2012), (De Villiers 2010).

To some extent, soft skills are considered to be circumstance-specific and locally relevant due to particular demand in the soft skills set by employers (Grugulis and Vincent 2009). However, there is growing evidence that soft skills are transferrable and can be applied across multiple job sectors (Robles 2012).

One of the main differences between technical and soft skills is measurability. While technical skills can be assessed quantitatively, the evaluation of soft skills is more complex and subjective due to their intangible nature. On the other hand, cultural aspects (Hofstede, Hofstede and Minkov 2010), differences in traditions and education may further complicate well-defined assessment of soft skills.

Recent decades demonstrate a growing demand by companies for soft skills (Teichler 1999). It is not surprising, given the ongoing globalization and innovation processes, which have increased the number of multi-cultural and cross-functional teams where there is an elevated demand for soft skills i.e. communication, interpersonal skills, emotional intelligence and others.

A report by Deloitte (Deloitte 2017) corroborates the importance of soft skills for business development. According to the forecast, soft skill intensive jobs will account for two-thirds of all jobs by 2030, compared to half of all jobs in the year 2000. In addition, the number of jobs in soft-skill intensive occupations is expected to grow at a 2.5 times 
higher rate than in the other occupancies. Thus, there is a clearly growing demand for soft skills projected for the near future.

Every job announcement published today either on a company website or in a specialized platform such as LinkedIn includes a decent number of requirements for soft skills. Another observation is that the proportion of soft skills required for the job prevails over technical skills for the managerial and executive job families, indicating that the soft skills is an inevitable part for people on the managerial track (Varis, Majaniemi and Wilderom 2018).

The growing demand for soft skills gives rise to various training programs and educational institutions aiming at teaching and development of soft skills of individuals at different levels of experience. Despite the wide spread of virtual trainings, educational videos available on different internet platforms, educational systems lack proper programs teaching soft skills and competencies (Bennett, Dunne and Carré 1999). Thus, Andrews and Higson point out to the education system enforced challenges which graduates experience when entering the labor market and trying to meet the needs of employers (Andrews and Higson 2008). Another study performed among Dutch higher education graduates revealed that technical competencies positively impacted the chances of graduates to match the job within the own professional domain, while non-technical competencies (soft skills) increased the chances of getting job and training opportunities also outside the own domain (Heijke, Meng and Ris 2003).

Cimatti emphasizes the important role of soft skills for the success of organizations and enterprises (Cimatti 2016). While an individual plays a fundamental role in the soft skill development, it is suggested that soft skills must be taught all the way from primary school and even before that within the family.

Many institutions begin to introduce pilot programs specifically focusing on addressing the gaps in acquiring developing business and soft skills. Bastos, Schleutker and Azevedo point out to the importance of soft skills for communication and adaptation as well as for employability reasons (Bastos, Schleutker and Azevedo 2018).

Richardi and Emanuel echo on the equal importance of soft skills as specific technical skills in today's labor market (Ricchiardi and Emanuel 2018). A program for theoretical and methodological reflection about soft skills' assessment was introduced in the University of Turin.

A report from McKinsey\&Company (Mourshed, Patel and Suder 2014) on the challenges of youth in Europe getting into the labor market also emphasizes gaps in the current education-to-employment path. Building the right skills is considered as one of the main roadblocks in finding a suitable job. More specifically, the report stresses that young people are often lacking a sufficient set of soft skills and that employers report on a shortage of soft skills such as spoken communication and work ethics. The challenge is that employers and providers do not work together to minimize the gaps.

Similar thoughts are presented by Tulgan in his book, where he elaborates on the importance of soft skills for successful employment of youth and points out to a growing gap in soft skill demand and offer (Tulgan 2015).

A thorough study on the situation regarding demand of soft skills from employers and ability of the employees to fulfil such demand was conducted by Schleutker, Caggiano and Coluzzi in the European labor market (Schleutker et al. 2019). In the study involving 64 managers, it has been reported that the significance of soft skills to employers seemed to vary depending on the working environment as well as the field. The authors conclude that for efficient soft skills training a classification needs to be developed and validated and a more targeted array of soft skills with respect to the labor market needs to be designed and implemented.

\subsection{Soft Skills Used in This Research}

Since there are various classifications for soft skills available in the academic literature, we have decided to use the soft skill list and classification in accordance with European Skills/Competencies, qualifications and occupations (ESCO): https://ec.europa.eu/esco/portal/skill

This classification has been applied by Schleutker et al. in the soft skills study conducted for the European Labor Market (Schleutker et al. 2019).

The classification has been updated with soft skills relevant to the case organization and modified in accordance with the research objectives of this study. The classification of the soft skills with a brief description of each skill is shown in Table 1. 
Table 1. Classification of soft skills used in this study

\begin{tabular}{|c|c|}
\hline Category & Soft skill \\
\hline \multirow{3}{*}{ Personal management } & Self-control and confidence \\
\hline & Commitment to the organization \\
\hline & Management of change \\
\hline \multirow{4}{*}{ Influence } & Communication skills \\
\hline & Empathy / Emotional Intelligence \\
\hline & Networking skills \\
\hline & Customer Orientation \\
\hline \multirow{2}{*}{ Thinking } & Use of knowledge \\
\hline & Strategic orientation \\
\hline \multirow{3}{*}{ Team management } & People management \\
\hline & Work in team \\
\hline & Intercultural skill \\
\hline \multirow{2}{*}{ Navigation } & Integration into the company \\
\hline & Knowledge of company's structure \\
\hline \multirow{2}{*}{ Goal Orientation } & Initiative \\
\hline & Planning and organizing \\
\hline
\end{tabular}

\subsection{Employee Resource Groups (ERG) as Platform for Employee Learning and Development}

Many organizations have established employee groups, unions and networks that at the end have different missions and goals. In literature, a term "employee resource group" or ERG is often used (in earlier studies the term "affinity groups" was frequently used (Douglas 2008; Welbourne, Rolf and Schlachter 2015)). ERGs can be social cause oriented (e.g. environmental views), professional oriented (e.g. engineers) or attribute oriented (origin (McPhee et al. 2017), gender, sexual orientation etc.) (Welbourne and McLaughlin 2013). ERGs have been playing an important role in addressing the physical and psychological safety of employees, especially of those which belong to more vulnerable minorities prone to prejudice, for example LGBT (McNulty et al. 2018). Within organizations, such groups exist to represent and promote interests of their members that in the professional world are related to development, career opportunities and fair treatment. ERG were also shown to promote inclusion practices in the organizations (Schmidt et al. 2012).

The employee resource groups may be viewed as a platform for cultivating and fostering inclusion practices as well as for developing soft skills in the workforce through which the best inclusive performance can be achieved.

A research study by Welbourne and McLaughlin showed a prominent role of the ERGs in the improvement of organizational performance (Welbourne and McLaughlin 2013). The ERGs were shown to provide employees with an engaging and fulfilling work experience, thus positively influencing productivity and efficiency of the workforce. Interestingly, The drive for success created within certain ERGs encouraged leadership to use this potential for the organization beyond the ERG's scope, thus demonstrating inside out impact of the ERG on the business that continues to grow (Welbourne, Rolf and Schlachter 2015).

Employees tend to join ERGs when seeking for new opportunities and to connect with the peers and leadership for learning and developing purposes as reported by Friedman and Craig (Friedman and Craig 2004). Learning can occur though formal activities and events, for example, leadership sessions, cultural events and speaker series. Additional learning activities include lunches, presentations, informational stands, and helping the personnel in developing inclusion (Colgan and McKearney 2012). According to Githens, ERGs organize and facilitate diversity education sessions and members can see how diversity is connected to the organizational development activities (Githens 2012).

A recent research by Green highlights that ERGs facilitate learning and development activities within the 
organizations (Green Wendy 2018). It has been reported that ERGs can act as internal advocates, promote networking and facilitate professional development and learning opportunities. ERGs can provide formal and informal learning opportunities. The customization of formal learning up to member interests can result in more efficacious experiences. On the other hand, the informal learning is essential to manage the organizational culture, and the unwritten norms in the company can help retain employees and promote their career development. In addition to the educational and developmental role, ERGs were shown to help companies reduce the workforce attrition and retain minority employees (Friedman and Holtom 2002).

Benefits from participation in the ERGs range from skill development to developing a better understanding of the organizational culture (Bierema 2005), (Colgan and McKearney 2012), (Korte, Brunhaver and Sheppard 2015). O'Neil reported ERGs provide a platform where senior management communicate and foster organizational culture and norms (O'Neil Deborah, Hopkins Margaret and Sullivan Sherry 2011).

Despite being a valuable addition to the organizations and having a business impact, ERGs still represent an unexplored area of research. There should be more empirical research to gain knowledge about the processes on how ERGs are impacting the workforce and facilitate employee learning and integration into organizations (Welbourne Theresa, Rolf and Schlachter 2017).

Employee participation in formal and informal learning is essential for the economic viability and competitive advantage of organizations (Noe 2014). Therefore, assessing the outcomes of competence development activities is important. However, this domain of human resources (HR) practice is often neglected because of factors that are not well understood. Wallo, Kock, Lundqvist and Coetzer (Wallo 2020) presented categories of factors that appear to enable and inhibit endeavors relating to the assessment of outcomes of competence development activities. Wallo et al. (2020) claim that the findings regarding to approaches to assessment have some important implications for HRD professionals. They suggest that they adopt a best-fit approach and learn to skillfully combine the wide array of methods and tools that are available for assessment, rather than seek to uncover a universal, best-practice assessment model (Tottell 2009). Thus there is a lack of simple tools and metrics for assessment of competency development (including learning via ERGs) that might affect efficiency of development programs in the organizations.

Thus, while there is a number of research studies showing a positive role of ERGs on learning and development of employees, the influence of ERGs on the development of soft skills appears to be underinvestigated, hence featuring a very interesting and useful field of research. Our research is dedicated to studying and evaluating the role of an ERG in the global organization on the soft skills learning and development of new employees. In addition we attempted to develop and validate an empirical competency assessment tool that will help competency assessment in the organizations.

The implications and learnings of the study may be helpful for both the employees and the organization to better understand the educational component of ERGs with respect to the soft skills training and potentially suggest improvements to close the gap between the demand for soft skills and their presence in the employees. On the other hand, we try to address the efficiency of the ERG with respect to its mission and goals and try to identify the most impactful areas for employees participating in the ERG. We included in the study an open question where employees were able to express their opinion, targeted at revealing the strong sides of ERG as well as the areas for attention.

\section{Research Questions and Methodology}

The main research questions to be answered in this study are the following:

- What are the soft skills relevant in the case organization?

- What is the impact of the employee resource group on the soft skills of participants?

- How important are certain soft skills to the participants of the employee resource group (ERG)?

○ Did participants of the ERG improve their soft skills through participation in the events organized ty the ERG?

- How did the participants improve their soft skills?

- If they did not improve - why is this the case?

The following project deliverables were set:

1. Measurable impact of the ERG in the development of employees' soft skills

2. An empirical tool (methodology) to assess ERG performance with an option to suggest improvements in the ERG activity (type of events, scope, etc.) 


\subsection{Survey Structure and Methods for Data Collection}

Quantitative data collection was accomplished through a designed questionnaire. For the case study, a methodology described by Lietz (Lietz 2008) has been applied. The questionnaire was constructed in accordance with recommendations on the quantitative research practices as reported by Boynton and Greenhalgh (Boynton and Greenhalgh 2004).

The survey was voluntary and anonymous, no personal information or data was asked from the participants. The participants were informed about the voluntary ground for participation and about the anonymous nature of the data collection.

\subsection{Statistical Data Analysis and Sample Size Calculation}

For the quantification analysis of the data obtained in this study, a statistical approach was used. The statistical analysis and visualization software package $\mathrm{JMP}^{\circledR}$ was used for data sorting, processing and statistical analysis:

https://www.jmp.com

The ERG of this study contained ca. 800 participants. For statistically relevant and correct conclusions, it was important to assess the minimum required sample size for data collection and processing. We used the methodology described by Krejcie and Morgan (Krejcie and Morgan 1970) for the calculation of the sample size for this study.

According to Krejcie and Morgan, the sample size is calculated using the following equation:

$$
\text { Sample size }=\frac{X^{2} \times N \times P \times(1-P)}{d^{2} \times(N-1)+X^{2} \times P \times(1-P)}
$$

Where $\mathrm{X}^{2}-$ a table value of Chi-Square for the desired confidence level -3.8416 for an assumed confidence level of 0.5 (relevant to most of the social studies)

$\mathrm{N}$ - Population size ( 800 at the moment of the survey)

$\mathrm{P}$ - Population proportion, assumed 0.5

$\mathrm{d}$ - Degree of accuracy, assumed 0.15

The calculated minimum sample size $=41$ required for the population of 800 participants. We managed to acquire responses from 44 participants, thus exceeding the minimum required sample size for statistically rigorous data processing and interpretation.

Efficiency of the ERG on the soft skill development was assessed by participants ranking the impact on the 1-5 scale, where $1=$ no impact, $3=$ moderate impact and $5=$ big impact. If participants considered a certain soft skill not applicable to them, they could choose the option " 0 ".

On the other hand, it was equally important to understand whether a particular soft skill was important and relevant to the employees. For this purpose, employees assessed the significance of soft skills on the $1-5$ scale, where $1=$ not important, $3=$ important and $5=$ very important. In case a certain skill was not relevant to the respondents, they could choose the option " 0 " = not applicable.

$$
\text { Percentage who improved the skill }(\%)=\mathrm{Fs}(3)+\mathrm{Fs}(4)+\mathrm{Fs}(5)
$$

Where $\mathrm{Fs}(3), \mathrm{Fs}(4)$ and $\mathrm{Fs}(5)$ is the percentage of respondents who chose answer 3 (moderate impact), 4 (impact) or 5 (big impact) when asked about a particular soft skill.

Percentage that did not improve the skill $(\%)=100-(\mathrm{Fs}(3)+\mathrm{Fs}(4)+\mathrm{Fs}(5))$

Where $\mathrm{Fs}(3), \mathrm{Fs}(4)$ and $\mathrm{Fs}(5)$ is the percentage of respondents who chose answer 3 (moderate impact), 4 (impact) or 5 (big impact) when asked about a particular soft skill.

$$
\text { Percentage who found the skill important }(\%)=\mathrm{Fi}(3)+\mathrm{Fi}(4)+\mathrm{Fi}(5)
$$

Where $\mathrm{Fi}(3), \mathrm{Fi}(4)$ and $\mathrm{Fi}(5)$ is the percentage of respondents who chose answer 3 (moderately important), 4 (important) or 5 (very important impact) when asked about a particular soft skill.

The research method we used in this study represents participants' evaluation of their own learning. Note, that we used a common type of research for social sciences and aimed at verifying the learning experience and not the objective learning.

On the other hand, our research represents a case study using both a quantitative and a qualitative research approach, i.e. a mixed-method approach. The purpose of using the representative sample size is for an ability to apply the 
results to the entire ERG population and to ensure that conclusions regarding the whole population (ERG) are reliable.

\section{Research Results}

\subsection{Learning Efficiency}

The analysis of soft skill learning efficiency by ERG participants in the case company is demonstrated in Figure 1. In addition, participants assessed the importance of certain soft skills to them. The learning efficiency will thus be assessed against the soft skill importance to participants.

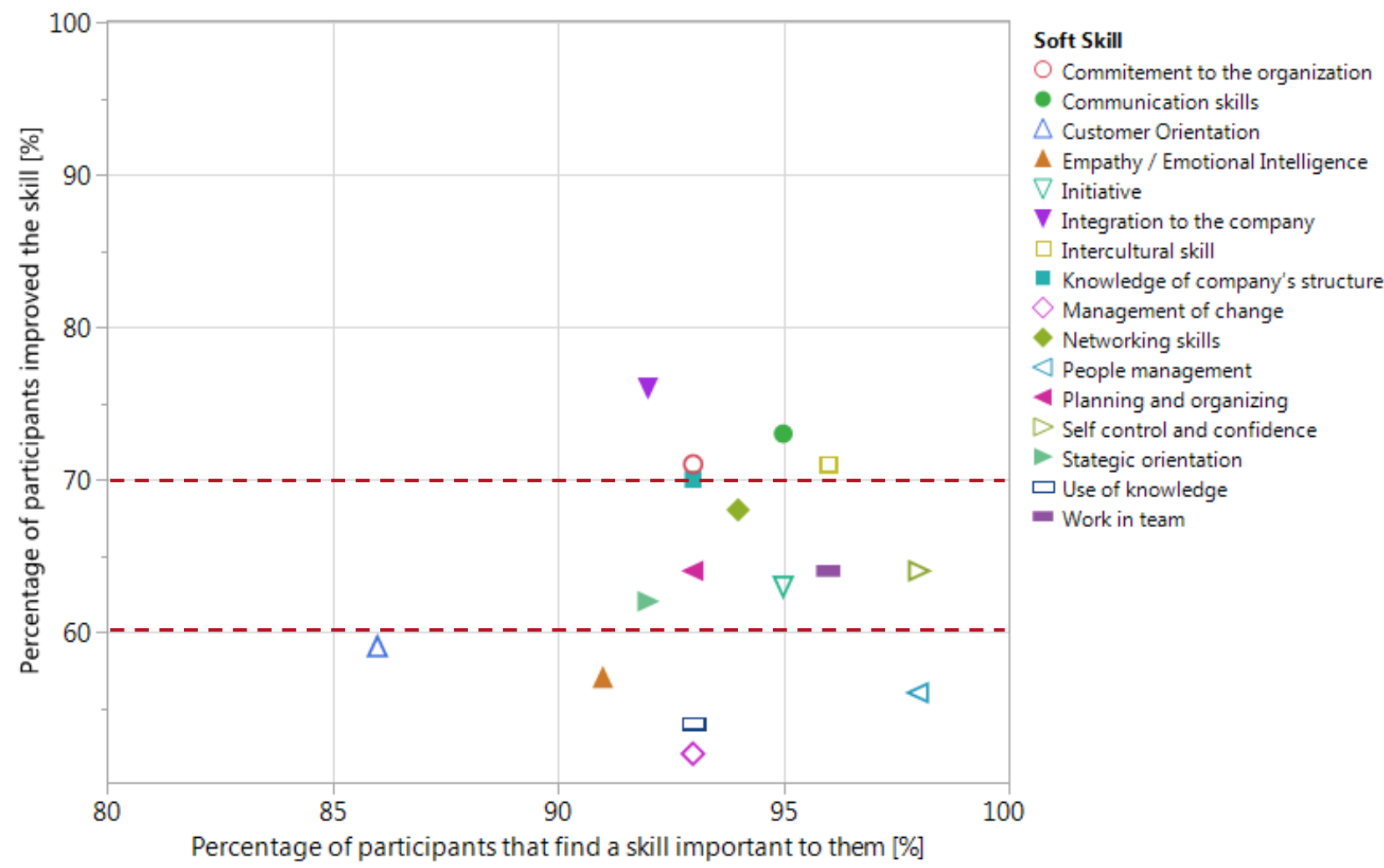

Figure 1. Score of a soft skill improvement plotted versus importance of this skill to participants

Figure 1 illustrates the overall correlation of soft skill importance with the degree of learning across all soft skill categories utilized in this study (see Table 1 for the soft skills classification used in this study).

A vast majority of soft skills proposed in the study was reported to be important for young professionals and received $90-98 \%$ on the importance scale. There was only one soft skill, "customer orientation", which received high but a slightly lower score of $86 \%$. These results could be explained by a few factors.

On the one hand, the survey in its present form did not provide additional information and clarification on the meaning of a certain soft skill; hence the lack of understanding of the meaning behind the skill and different interpretations by respondents could have caused a lower importance ranking. On the other hand, not all survey respondents work directly with customers and therefore might have considered this soft skill less relevant for them.

Figure 2 provides another view on the same data set and gives a breakdown of soft skills per category, demonstrating that there was not a particular category to stand out based on the learning degree. A quite substantial overlap has been observed across categories, although some trends are observed.

The navigation category scored higher than goal orientation and thinking categories, while the spread across learning degree scores for influence, personal and team management categories does not really allow for making a strong conclusion. 
Given the focus of young professionals' ERG on networking and facilitating navigation in the organization for the participants, the leading position of the navigation soft skill category does not seem to be surprising.

On the importance, ranking three categories showed a distinction: team management $>$ goal orientation $>$ navigation $\sim$ thinking. It must be noted that all soft skills categories scored high, therefore the difference cannot be considered substantial and should be understood in terms of trends rather than absolute numbers. It appears that the participants valued the most personal and team management skills with self-control and confidence and people management showing the highest score. The young professionals' ERG organizes sessions with leaders regularly and it does not seem surprising that the people leadership track attracts young talent. This trend is reflected in the importance of soft skill for the ERG participants who aspire to become future leaders.

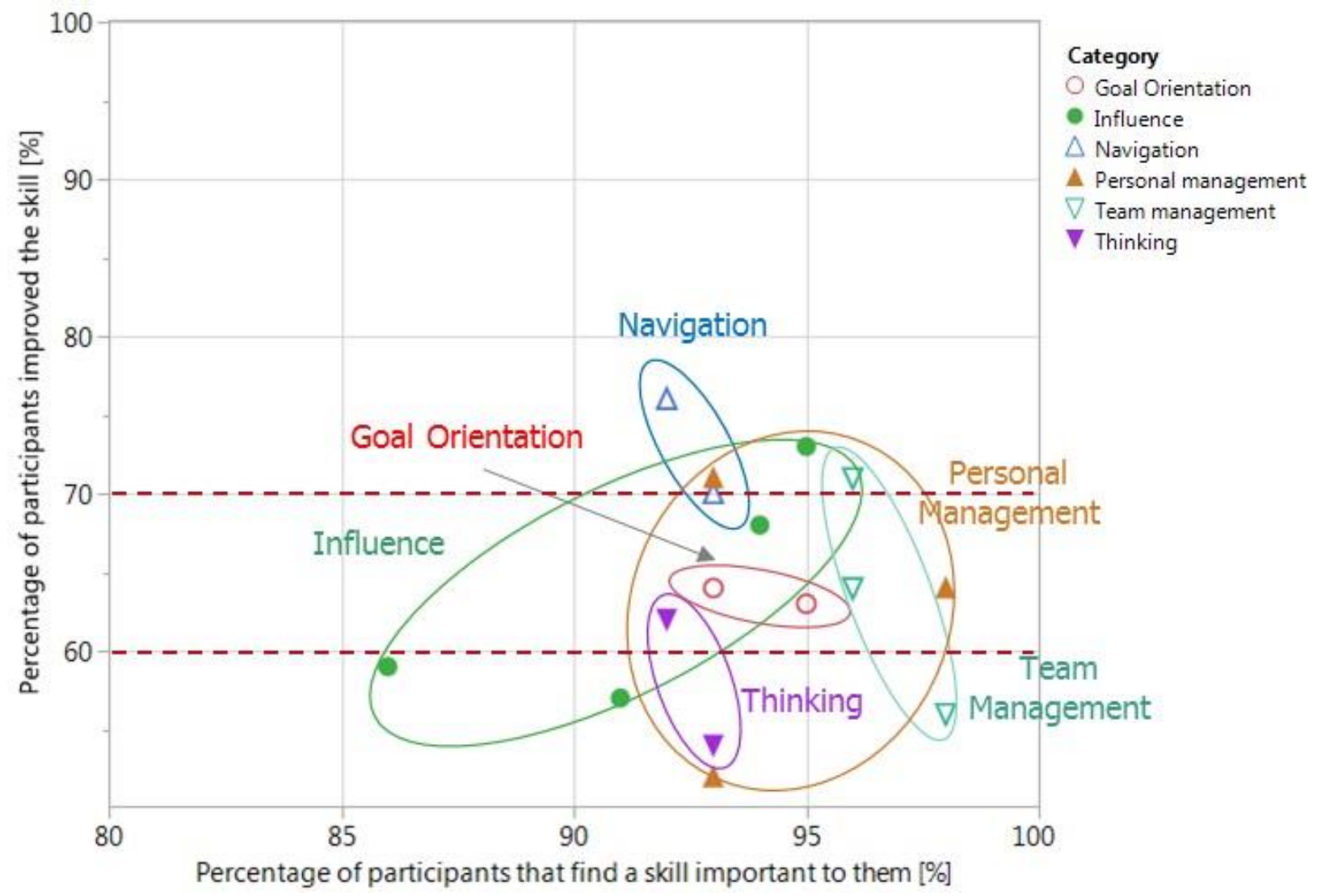

Figure 2. Score of a soft skill improvement versus its importance broken down by soft skill category

\subsection{Metrics for Evaluation of Soft Skills Learning}

The metrics for evaluation of the success of participants' soft skill learning can be introduced using the importance and learning degree scores. We can arbitrarily group soft skills, regardless their category, based on the learning degree:

- Group 1: 70+\% - the impact of the ERG on these soft skills can be deemed substantial

- Group 2: 60-70\% - the impact of the ERG on these skills was reasonable, some improvements may be suggested

- Group 3: 60\% and below - the impact of the ERG on these skills was moderate and deserves closer attention

Soft skills grouping is reported in Table 2. 
Table 2. Soft skill grouping based on learning degree

\begin{tabular}{|c|c|c|c|}
\hline Soft skill & Soft skill category & $\begin{array}{c}\text { Learning } \\
\text { degree }[\%]\end{array}$ & Group \\
\hline Integration into the company & Navigation & 76 & 1 \\
\hline Communication skills & Influence & 73 & 1 \\
\hline Commitment to the organization & $\begin{array}{c}\text { Personal } \\
\text { management }\end{array}$ & 71 & 1 \\
\hline Intercultural skills & Team management & 71 & 1 \\
\hline $\begin{array}{c}\text { Knowledge of company's } \\
\text { structure }\end{array}$ & Navigation & 70 & 1 \\
\hline Networking skills & Influence & 68 & 2 \\
\hline Self-control and confidence & $\begin{array}{c}\text { Personal } \\
\text { management }\end{array}$ & 64 & 2 \\
\hline Work in team & Team management & 64 & 2 \\
\hline Planning and organizing & Goal Orientation & 64 & 2 \\
\hline Initiative & Goal Orientation & 63 & 2 \\
\hline Strategic orientation & Thinking & 62 & 2 \\
\hline Customer Orientation & Influence & 59 & 3 \\
\hline Empathy / Emotional Intelligence & Influence & 57 & 3 \\
\hline People management & Team management & 56 & 3 \\
\hline Use of knowledge & Thinking & 54 & 3 \\
\hline Management of change & $\begin{array}{c}\text { Personal } \\
\text { management }\end{array}$ & 52 & 3 \\
\hline
\end{tabular}

\subsection{Analysis of Soft Skills Relevant to ERG's Mission and to the Organization's Core Competencies}

It seems useful to analyze the soft skill learning by participants through the prism of matching with the ERG mission and vision as well as to estimate to what degree the skills included in the core competencies for the organization are impacted.

The vision and mission of the Young Professionals' ERG focus on providing new employees with an opportunity to network and better integrate to the organization as well as learn its structure. Through interactions with peers and leaders, participants are also expected to improve communications skills. Based on vision and mission of the network, the following six skills were selected as the most relevant to the ERG scope (soft skill category mentioned in the brackets):

1. Communication skills (Influence)

2. Networking skills (Influence)

3. Work in team (Team management)

4. Intercultural skills (Team management)

5. Integration to the company (Navigation)

6. Knowledge of company's structure (Navigation)

Figure 3 shows a similar analysis, which was performed across all the soft skills for the skills that are corresponding to the ERG mission and vision. 


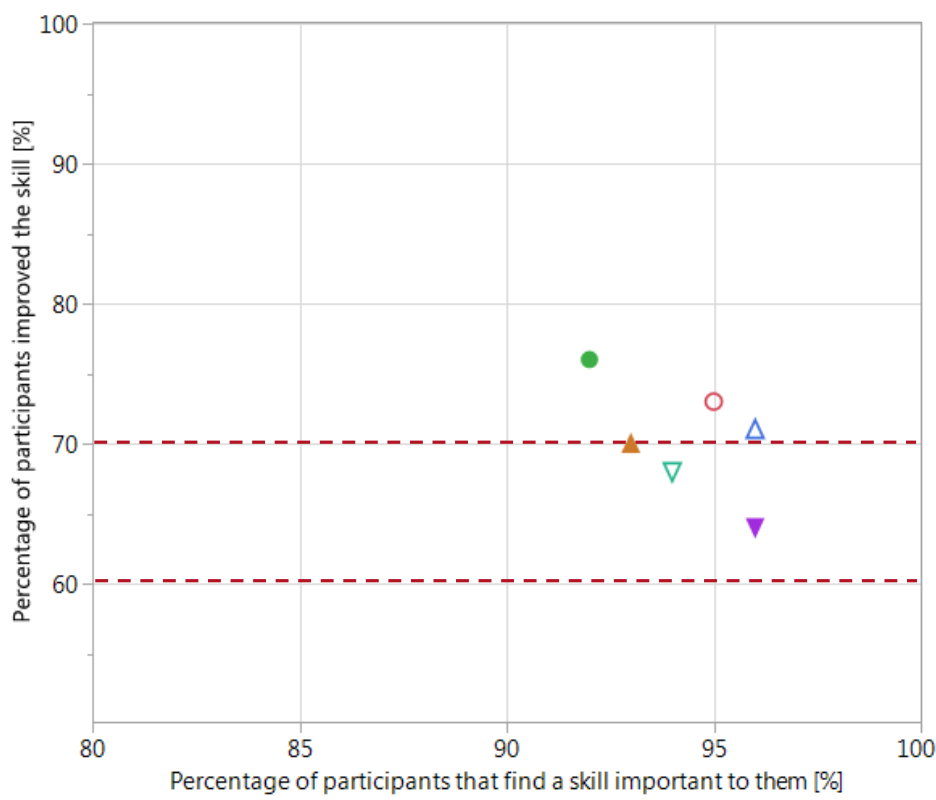

\section{Soft Skill}

Communication skills

- Integration to the company

$\triangle$ Intercultural skill

$\Delta$ Knowledge of company's structure

$\nabla$ Networking skills

$\nabla$ Work in team

Figure 3. Analysis of learning degree and importance of soft skills that correspond to the ERG mission and vision

All six selected soft skills scored above $60 \%$, indicating that the ERG provides a learning platform for improving some soft skills for the participants. The highest score was achieved by the integration to the company skill, being one of the closest to the ERG scope and targets.

A similar type of analysis was performed for soft skills that fall into one of the core competency categories relevant to the organization: customer focus, innovation, leadership and teamwork. In total, seven skills from our soft skill list were selected and matched with the corresponding core competency category. Efficiency of the soft skill learning by participants in the ERG events is evaluated against the importance of the soft skill to the participants. The data is displayed in Figure 4.
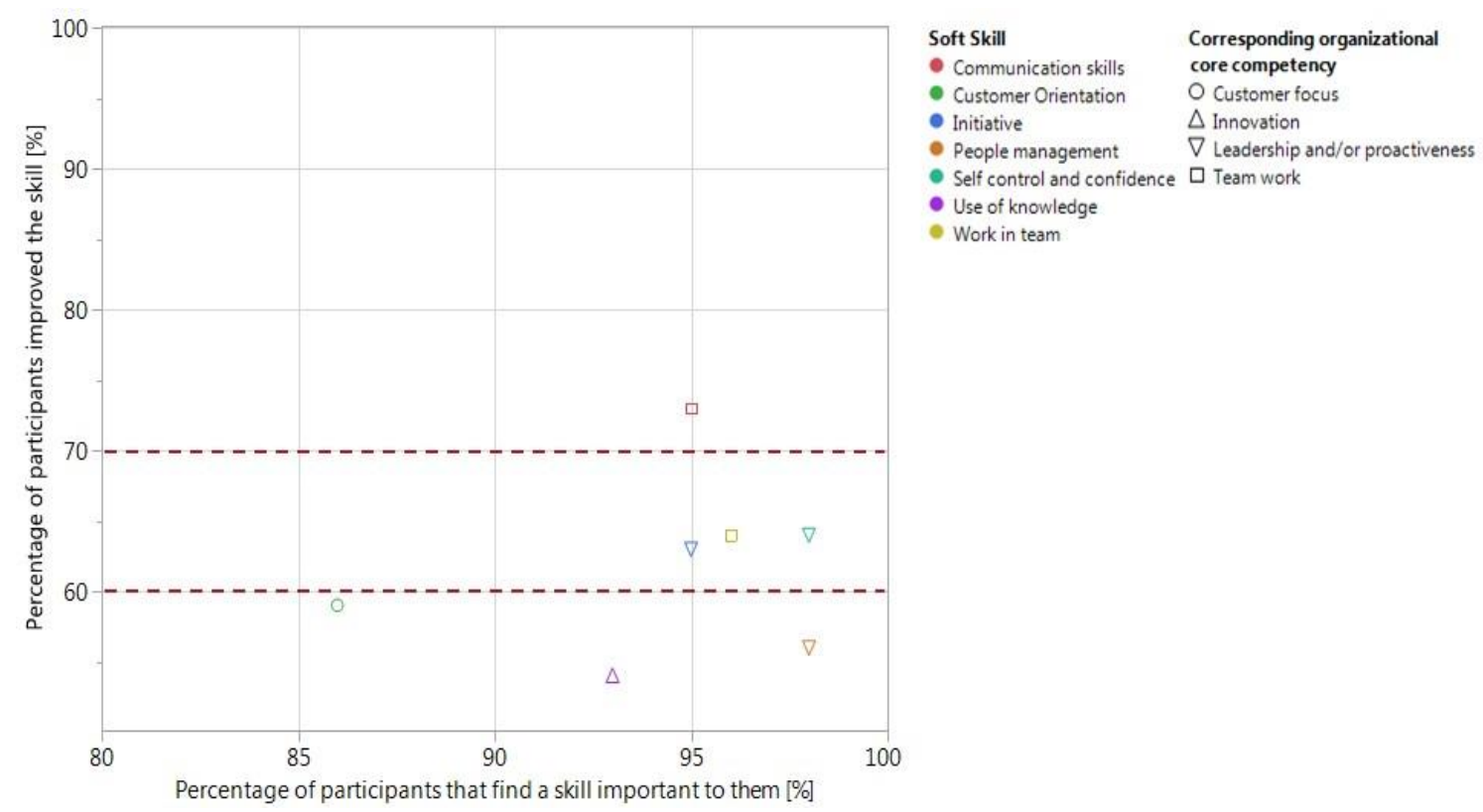

Figure 4. Analysis of learning degree and importance of soft skills that correspond to the organizational core competencies 
In order to assess the impact of the ERG on the soft skill learning, it would be useful to understand how participants learned the skills that match with the ERG mission and vision and correspond to the competencies relevant to the organization.

For this purpose, participants were asked to express how they improved a certain soft skill. Moreover, the participants were able to choose among the following options:

- Improved soft skill via interaction with leaders

- Improved soft skill via interaction with other participants

- Improved soft skill via interaction with leaders and other participants

- Other

- Did not improve the soft skill

Note that multiple options were allowed to be selected for the answer; hence, the total percentages may exceed $100 \%$.

\subsection{How Participants Learned and Improved Soft Skills Compared to the ERG's Targets}

Table 3 summarizes the data for soft skills that either match with the ERG scope or correspond to the organizational competencies.

Table 3. Data on how participants learned and improved soft skills corresponding to the ERG scope

\begin{tabular}{|c|c|c|c|c|c|c|c|c|}
\hline \multicolumn{9}{|c|}{ Improved through interaction with } \\
\hline Soft skill & $\begin{array}{l}\text { Soft skill } \\
\text { category }\end{array}$ & $\begin{array}{c}\text { Aligns } \\
\text { with } \\
\text { ERG }\end{array}$ & $\begin{array}{c}\text { Aligned } \\
\text { organizationa } \\
\text { l competency }\end{array}$ & Leaders & $\begin{array}{c}\text { Other } \\
\text { partici } \\
\text { pants }\end{array}$ & $\begin{array}{c}\text { Leaders } \\
\text { and other } \\
\text { participants }\end{array}$ & Other & $\begin{array}{l}\text { I did not } \\
\text { learn or } \\
\text { improve } \\
\text { this skill }\end{array}$ \\
\hline $\begin{array}{l}\text { Self-control and } \\
\text { confidence }\end{array}$ & $\begin{array}{c}\text { Personal } \\
\text { management }\end{array}$ & & $\begin{array}{l}\text { Leadership } \\
\text { and/or } \\
\text { proactiveness }\end{array}$ & 57 & 22 & 50 & 9 & 22 \\
\hline $\begin{array}{l}\text { Communication } \\
\text { skills }\end{array}$ & Influence & yes & Teamwork & 70 & 16 & 64 & 9 & 16 \\
\hline $\begin{array}{c}\text { Networking } \\
\text { skills }\end{array}$ & Influence & yes & & \multicolumn{5}{|c|}{ Data not available } \\
\hline $\begin{array}{l}\text { Customer } \\
\text { orientation }\end{array}$ & Influence & & $\begin{array}{l}\text { Customer } \\
\text { focus }\end{array}$ & 45 & 16 & 27 & 18 & 30 \\
\hline $\begin{array}{c}\text { Use of } \\
\text { knowledge }\end{array}$ & Thinking & & Innovation & 52 & 18 & 48 & 16 & 23 \\
\hline $\begin{array}{c}\text { People } \\
\text { management }\end{array}$ & $\begin{array}{c}\text { Team } \\
\text { management }\end{array}$ & & $\begin{array}{l}\text { Leadership } \\
\text { and/or } \\
\text { proactiveness }\end{array}$ & 43 & 18 & 27 & 14 & 34 \\
\hline Work in team & $\begin{array}{c}\text { Team } \\
\text { management }\end{array}$ & yes & & 48 & 34 & 43 & 9 & 20 \\
\hline $\begin{array}{l}\text { Intercultural } \\
\text { skills }\end{array}$ & $\begin{array}{c}\text { Team } \\
\text { management }\end{array}$ & yes & & 48 & 34 & 43 & 9 & 20 \\
\hline $\begin{array}{l}\text { Integration into } \\
\text { the company }\end{array}$ & Navigation & yes & & 66 & 16 & 50 & 16 & 16 \\
\hline
\end{tabular}




\begin{tabular}{|c|c|c|c|c|c|c|c|c|}
\hline $\begin{array}{c}\text { Knowledge of } \\
\text { company's } \\
\text { structure }\end{array}$ & Navigation & yes & & 48 & 34 & 43 & 9 & 20 \\
\hline Initiative & $\begin{array}{c}\text { Goal } \\
\text { Orientation }\end{array}$ & & $\begin{array}{l}\text { Leadership } \\
\text { and/or } \\
\text { proactiveness }\end{array}$ & 62 & 18 & 55 & 11 & 23 \\
\hline
\end{tabular}

Quite clearly, interaction with leaders was perceived to have a substantial impact on the improvement of soft skills among the respondents. There were three skills where employees expressed substantial improvements due to interaction with the leaders. Thus, $70 \%$ of respondents indicate that they have improved the communication skill via interaction with leaders, while only $16 \%$ benefited from the interaction with other participants in this case. A similar result was observed for "integration into the company" skill where $66 \%$ and $16 \%$ expressed improvements via interaction with leaders and other participants, respectively. Another soft skill where participants highlighted progressive contributions from the interaction with leaders was "initiative", and $62 \%$ and $18 \%$ indicated contributions from the interaction with leaders and participants, respectively.

The top three skills that employees reported to have improved via interaction with the participants in the ERG events were work in team, intercultural skills (both belong to the "team management" category) and knowledge of company's structure.

Learning of the intercultural skills and expanding knowledge about different cultures occurred via interaction with representatives from various cultures, and large networking sessions where participants got an opportunity to interact with each other definitely helped to improve this skill.

Participants reflected that they managed to improve the knowledge about the company's structure from other employees. These results could be explained from the perspective of attendance at the ERG events by employees across departments and job families. The ERG currently has a very diverse list of participants that represent almost every department in the company, from customer service to R\&D organization.

The networking events where employees have an opportunity to meet colleagues from different departments help them to learn about different roles and better understand how various departments interact with each other. In large organizations with high complexity, people often focus on a particular role and may miss the bigger picture of different roles existing in the organization. Existing platforms provided by human resources do not always cover the need for information. A direct interaction with peers from different roles in an informal setting provides in this respect a unique opportunity for employees to discuss and ask questions from each other and learn much more efficiently about different roles and responsibilities rather than gaining information on the web-based platforms.

One of the main reasons why employees did not improve a particular skill could be the scope and mission of the ERG that is not per se a learning body but rather a social network that also provides opportunities to learn and improve. For example, according to the data presented in Table 3,34\% of the respondents mentioned that they did not learn People Management Skill and 30\% did not improve their Customer Orientation Skill. These are very important and, at the same time, quite specific skills which require a dedicated platform for learning and practicing. The networking events that constitute the core of the ERG events do not provide right platform for teaching and learning such skills beyond the selected ones when leaders highlight cases from their careers or share their perspectives on interaction with customers.

Some employees participating in the ERG had sufficient experience and knowledge, hence it is more difficult for them to learn unless dedicated soft skill learning sessions are organized. Another factor highlighted by participants was related to the public nature of events that may not be suitable for all employees. This comment demonstrates that different learning approaches are required in the organization to achieve a high learning degree among different employees and there is no one "golden" methodology that can fit all employees.

\section{Summary and Conclusions}

Organizations nowadays demonstrate a growing demand for high quality soft skills in the workforce. While there are existing training programs within the organizations aiming to provide relevant trainings to the employees and help them develop soft skills relevant for the job, it appears that such programs do not fully address the demand and do not cover the entire spectrum of soft skills. 
In this study, employee resource groups (ERG) were explored as a potential platform for soft skills learning and development. The case study involved an ERG "Young Professionals" comprising ca. 800 participants and focusing on new employees.

The ERG has a positive effect on the soft skills development. Employees improved soft skills that match the scope of the ERG (networking and communication skills, work in team, intercultural skills) through interaction with leaders and peers in the events.

Interestingly, employees recognized that more learning happened during interaction with leaders than with peers. Still, interaction with peers helped employees to improve the work in the team and intercultural skills and to learn the structure of the organization. Thus, for efficient learning of the soft skill, a single type of interaction is not sufficient, and therefore mixed models can be with engaging interaction among employees as well as with leaders.

Some soft skills developed less efficiently via ERG (for example customer orientation and people management) and the proposed reason was attributed to the absence of a dedicated sessions and lack of overlap with the ERG scope. It can be recommended that the ERGs focus on sessions and organize focused events so that employees can learn and improve soft skills more efficiently.

The main factors hampering their learning of soft skills via ERG included:

- existing experience (no need for further skill development)

- lack of focused sessions

- public nature of events, passive attendance with limited interaction

Eventually, while the initial ERG mission and scope do not directly relate to the soft skill education and training purposes, the current research demonstrates that employee resource groups and internal company networks can be fruitful platforms for enabling employees' development and cross-functional learning.

In this respect, ERGs are viewed as a complimentary body and additional resource to the existing soft skill trainings and programs in the organization that can help close the gaps and facilitate soft skill development in the workforce.

With a growing demand in the organizations for quantifying the deliverables and merits of ERGs (Welbourne and McLaughlin 2013), the present study has provided and successfully implemented an empirical methodology for assessment of the ERG's impact on employees' soft skills. Thus, the study offers a tool for quantification of the ERG performance and exemplifies how opportunities for improvements can be identified. Similar analysis with adjusted metrics can be leveraged and adapted to other organizations that actively utilize and promote ERGs to open avenues for creating a strong business case for ERGs in the organizations.

\section{Discussion, Contribution and Suggestions}

The current study revealed that some soft skills can be developed in employee resource groups (ERGs) in the interaction between management and new employees. On the other hand, some soft skills improved weakly: customer orientation, emotional intelligence, people management, use of knowledge and change management. Most likely, their development would require real business case problems as well as solving them in small groups whose activities could be facilitated by the management. Their development would require better re-focusing and planning of learning by corporate management and human resource management of ERGs.

The main contribution of this study is probably that certain soft skills do not seem to develop on their own in the interaction between management and new employees, but organized learning around certain focused issues, e.g., customer satisfaction, and related real business cases and problems. These cases and problems should be found in the organization so that employees feel they are related to the real work that concerns them, so that they have a real motivation to learn something concrete and useful at work. This is where the ERG can provide a platform and serve as a learning ground for employees. As there is more potential for further implementation in the case organization, it can be argued that employee resource groups (ERGs) are still an untapped way to develop soft skills.

Another question of even more fundamental nature relates to whether the purpose of employee resource groups (ERGs) primarily is to integrate new employees into the prevailing organizational culture of the company and hereby the purpose of learning is primarily monotonous. On the other hand, does the company management also want to learn from new employees, i.e. at the same time develop and foster the existing corporate culture? Research by Green (Green Wendy 2018) emphasizes that ERGs can serve as source of information and feedback from employees to the management and also that the informal learning via ERG helps to manage the organizational culture and articulate unwritten norms of the company. 
For the latter option, honest opinions about the company and its ways of working can be systematically and regularly obtained from new employees through surveys as well as via dispute reporting and management team discussions. On the other hand, new employees, especially younger ones, would also be required to see with fresh eyes and question the status quo and existing processes in the company and have appointed managers as mentors in their ERG groups. However, all this requires systematic work and the development and visualization and structuring of this kind of HR processes. Indeed, research has revealed that the knowledge and wonder brought in by new employees can be a very useful source for an organization to develop its own culture and activities, although usually well neglected (Tuominen 2017).

These options are illustrated in the following Figure 5:

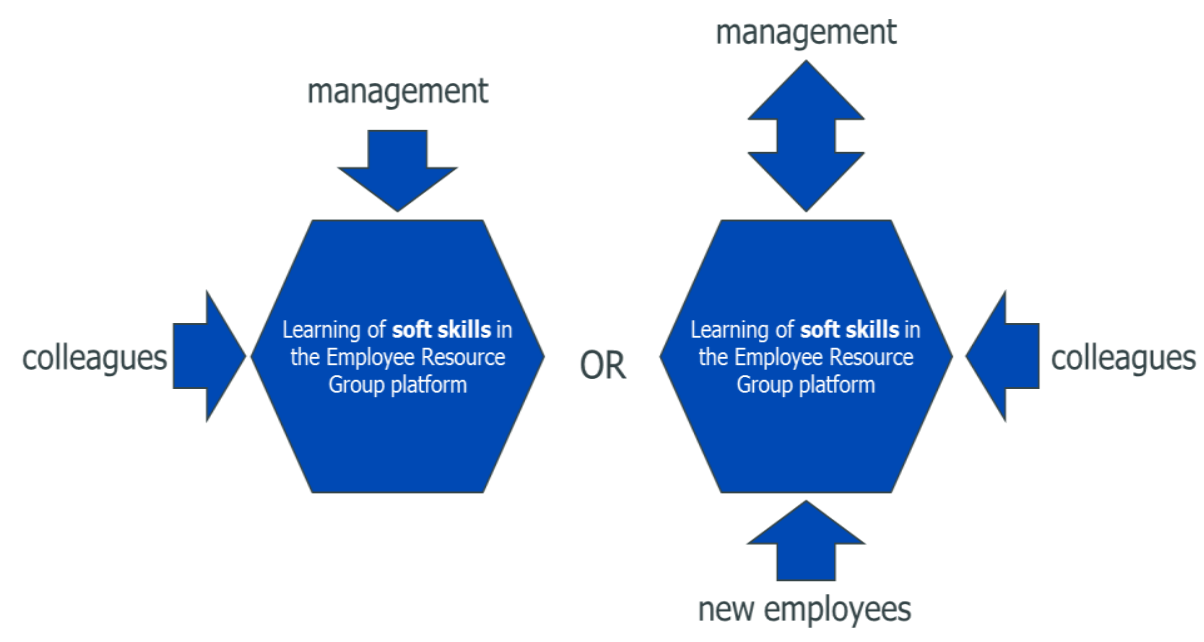

Figure 5. Two alternatives of soft skills development: two- or three-way learning

Despite the fact that the alternatives illustrated in Figure 5 do not provide any new options per se, it is still important to determine a learning and developing strategy and objectives in an organization, in other words how the teaching functions are distributed and who is considered as the learning object.

The integration and socialization of new employees alone to the prevailing management and organizational culture seems limited. We propose a multidimensional paradigm where everyone develops everything, i.e. the management and organizational culture should also be considered as objects of development and the new employees act as good tools in it (Tuominen 2017). This direction can be recommended based on this study.

The third contribution of the study is related to the fact the ERGs do not directly promote career development. This finding provides an alternative perspective on the role of ERGs in career development to that reported in other studies (Bierema 2005), (O'Neil Deborah, Hopkins Margaret and Sullivan Sherry 2011) and shows that mechanisms for internal mobility and career advancement are yet to be developed for ERGs.

Chatterji et. al (Chatterji, de Figueiredo and Rawley 2016) pointed out in their study of the financial sector that if the work community provides an opportunity for experimentation, employees can learn about their skills and preferences and this will enable them to gain a new position in a new company. ERG can serve as platform for experimentation and help human resources management develop and retain talent.

Relying on the three points mentioned above, we postulate that the ERGs present a completely untapped opportunity for the development of new staff and also its own organization and culture.

\section{Acknowledgements}

The authors acknowledge Mrs. Elli Sillanpää for providing language help during preparation of this article and participants of the ERG "Young Professionals" for participation in the research survey. This research did not receive any specific grant from funding agencies in the public, commercial, or not-for-profit sectors.

\section{References}

Andrews, J., \& Higson, H. (2008). Graduate Employability, 'Soft Skills' Versus 'Hard' Business Knowledge: A European Study. Higher Education in Europe, 33(4), 411-22. https://doi.org/10.1080/03797720802522627 
Bastos, S., Schleutker, K., \& Azevedo, L. (2018). How to facilitate development of soft skills in business studies? Description of a Portuguese and a Finnish pilot. Journal of Finnish Universities of Applied Sciences.

Bennett, N., Dunne, E., \& Carré, C. (1999). Patterns of core and generic skill provision in higher education. Higher Education, 37(1), 71-93. https://doi.org/10.1023/A:1003451727126

Bierema, L. L. (2005). Women's Networks: A Career Development Intervention or Impediment?. Human Resource Development International, 8(2), 207-24. https://doi.org/10.1080/13678860500100517

Boynton, P., \& Greenhalgh, T. (2004). Selecting, designing, and developing your questionnaire. BMJ, 328(7451), 1312-15.

Bughin, J., Hazan, E., Lund, S., Dahlström, P., Wiesinger, A., \& Subramaniam, A. (2018). Skill shift automation and the future of the workforce.

Chatterji, A. K., de Figueiredo, R. J. P., \& Rawley, E. (2016). Learning on the Job? Employee Mobility in the Asset Management Industry. Management Science, 62(10), 2804-19.

Cimatti, B. (2016). Definition, development, assesment of soft skills and their role for the quality of organizations and eterprises. International Journal for Quality Research, 10(1), 97-130.

Colgan, F., \& McKearney, A. (2012). Visibility and voice in organisations: Lesbian, gay, bisexual and transgendered employee networks. Equality, Diversity and Inclusion: An International Journal, 31(4), 359-78.

De Villiers, R. (2010). The incorporation of soft skills into accounting curricula: preparing accounting graduates for their unpredictable futures. Meditari: Research Journal of the School of Accounting Sciences, 18(2), 1-22.

Deloitte. (2017). Soft skills for business success.

Douglas, P. H. (2008). Affinity groups: Catalyst for inclusive organizations. Employment Relations Today, 34(4), 11-18. https://doi.org/10.1002/ert.20171

ESCO. (2020). ESCO: European Skills/Competences, qualification and Occupations.

Friedman, R. A., \& Craig, K. M. (2004). Predicting Joining and Participating in Minority Employee Network Groups. Industrial Relations: A Journal of Economy and Society, 43(4), 793-816. https://doi.org/10.1111/j.0019-8676.2004.00362.x

Friedman, R. A., \& Holtom, B. (2002). The effects of network groups on minority employee turnover intentions. Human Resource Management, 41(4), 405-21. https://doi.org/10.1002/hrm.10051

Gilbert, R., Balatti, J., Turner, P., \& Whitehouse, H. (2004). The generic skills debate in research higher degrees. Higher Education Research \& Development, 23(3), 375-88. https://doi.org/10.1080/0729436042000235454

Githens, R. P. (2012). Organization Change and Social Organizing Strategies: Employee-Initiated Organization Development. Human Resource Development Quarterly, 23(4), 487-518.

Green, W. M. (2018). Employee resource groups as learning communities. Equality, Diversity and Inclusion: An International Journal, 37(7), 634-48. https://doi.org/10.1108/EDI-11-2016-0085

Grugulis, I., \& Vincent, S. (2009). Whose skill is it anyway?: 'soft' skills and polarization. Work, Employment and Society, 23(4), 597-615. https://doi.org/10.1177/0950017009344862

Heijke, H., Meng, C., \& Ris, C. (2003). Fitting to the job: the role of generic and vocational competencies in $\begin{array}{llll}\text { adjustment and } & \text { Labour }\end{array}$ https://doi.org/10.1016/S0927-5371(03)00013-7

Hofstede, G., Hofstede, G. J., \& Minkov, M. (2010). Cultures and organizations. McGraw Hill.

Korte, R., Brunhaver, S., \& Sheppard, S. 2015). (Mis)Interpretations of Organizational Socialization: The Expectations and Experiences of Newcomers and Managers. Human Resource Development Quarterly, 26(2), 185-208. https://doi.org/10.1002/hrdq.21206

Krejcie, R. V., \& Morgan, D. W. (1970). Determining Sample Size for Research Activities. Educational and Psychological Measurement, 30(3), 607-10. https://doi.org/10.1177/001316447003000308

Lietz, P. (2008). Questionnaire Design in Attitude and Opinion Research: Current State of an Art. Priorisierung in der Medizin, 655(13).

McNulty, Y., McPhail, R., Inversi, C., Dundon, T., \& Nechanska, E. (2018). Employee voice mechanisms for lesbian, gay, bisexual and transgender expatriation: the role of Employee-Resource Groups (ERGs) and allies. The International Journal of Human Resource Management, 29(5), 829-56. https://doi.org/10.1080/09585192.2017.1376221 
McPhee, D., Julien, M., Miller, D., \& Wright, B. (2017). Smudging, connecting, and dual identities: case study of an aboriginal ERG. Personnel Review, 46(6), 1104-19. https://doi.org/10.1108/PR-10-2015-0270

Mourshed, M., Patel, J., \& Suder, K. (2014). Education to employment: Getting Europe's youth into work.

Noe, R. A., Clarke, A. D., \& Klein, H. J. (2014). Learning in the twenty-first-century workplace. Annual Review of Organizational Psychology and Organizational Behavior, 245-75. https://doi.org/10.1146/annurev-orgpsych-031413-091321

O'Neil Deborah, A., Hopkins, M., M., \& Sherry, E. S. (2011). Do women's networks help advance women's careers? Differences in perceptions of female workers and top leadership. Career Development International, 16(7), 733-54. https://doi.org/10.1108/13620431111187317

Ricchiardi, P., \& Emanuel, F. (2018). Soft Skill Assessment in Higher Education. Journal of Educational, Cultural and Psychological Studies, 18, 21-53. https://doi.org/10.7358/ecps-2018-018-ricc

Robles, M. M. (2012). Executive Perceptions of the Top 10 Soft Skills Needed in Today's Workplace. Business Communication Quarterly, 75(4), 453-65. https://doi.org/10.1177/1080569912460400

Rukshar, M., \& Smrutihara, B. (2012). Soft skills in status QUO. International Journal of Physical and Social Sciences, 2(5), 212-23.

Schleutker, K., Caggiano, V., Coluzzi, F., \& Luján, J. L. P. (2019). Soft Skills and European Labour Market: Interviews with Finnish and Italian Managers. Journal of Educational, Cultural and Psychological Studies, 19, 123-44. https://doi.org/10.7358/ecps-2019-019-schl

Schmidt, S. W., Githens, R. P., Rocco, T. S., \& Kormanik, M. B. (2012). Lesbians, Gays, Bisexuals, and Transgendered People and Human Resource Development: An Examination of the Literature in Adult Education and Human Resource Development. Human Resource Development Review, 11(3), 326-48. https://doi.org/10.1177/1534484312447193

Teichler, U. (1999). Research on the relationships between higher education and the world of work: Past achievements, problems and new challenges. Higher Education, 38(2), 169-90. https://doi.org/10.1023/A:1003761214250

Tottell, B., Blackler, M., Toulson, P., \& Dewe, P. (2009). Metrics: HRM's holy grail? A New Zealand Case Study." Human Resource Management Journal, 19(4), 375-92. https://doi.org/10.1111/j.1748-8583.2009.00108.x

Tulgan, B. (2015). Bridging the Soft Skills Gap: How to Teach the Missing Basics to Todays Young Talent. Hoboken, New Jersey (USA): John Wiley \& Sons. https://doi.org/10.1002/9781119171409

Tuominen, L. (2017). Tulokkaan tieto organisaatiossa - kilpailuedun lähde vai hyödyntämätön resurssi/Knowledge that newcommers bring - competitive advantage or unused asset. Turku (Finland): Turku University of Applied Sciences.

Varis, K., Majaniemi, N., \& Wilderom, C. P. M. (2018). Recruiting Happy, Socio-emotionally Balanced and Mature Managers in Finland and Elsewhere. Journal of Leadership, Accountability and Ethics, 15(3), 147-62. https://doi.org/10.33423/jlae.v15i3.1253

Wallo, A., Kock, H., Lundqvist, D., \& Coetzer, A. (2020). Understanding Factors That Enable and Inhibit Assessment of Outcomes of Competence Development. Human Resource Development Review, 19(4), 384-421. https://doi.org/10.1177/1534484320943332

Welbourne, T. M., \& McLaughlin, L. L. (2013). Making the Business Case for Employee Resource Groups. Employment Relations Today, 40(2), 35-44. https://doi.org/10.1002/ert.21409

Welbourne, T. M., Rolf, S., \& Schlachter, S. (2015). Employee Resource Groups: An Introduction, Review and Research Agenda. Center for Effective Organizations, 1-35. https://doi.org/10.5465/ambpp.2015.15661abstract

Welbourne, T. M., Rolf, S., \& Schlachter, S. (2017). The case for employee resource groups: A review and social identity theory-based research agenda. Personnel Review, 46(8), 1816-34. https://doi.org/10.1108/PR-01-2016-0004

\section{Copyrights}

Copyright for this article is retained by the author(s), with first publication rights granted to the journal.

This is an open-access article distributed under the terms and conditions of the Creative Commons Attribution license (http://creativecommons.org/licenses/by/4.0/). 